\title{
Configurações
}

Revista de sociologia

\section{Pós-memória como herança: fotografia e testemunho do "retorno" de África}

Postmemory as an inheritance: photo and testimony of the "return" of Africa

La postmémoire comme héritage : photographie et témoignage du "retour" d'Afrique

\section{Elsa Peralta e Joana Gonçalo Oliveira}

\section{(2) OpenEdition}

\section{Journals}

Edição electrónica

URL: http://journals.openedition.org/configuracoes/3290

DOI: $10.4000 /$ configuracoes.3290

ISSN: 2182-7419

\section{Editora}

Centro de Investigação em Ciências Sociais

\section{Edição impressa}

Data de publição: 27 Junho 2016

Paginação: 181-197

ISSN: 1646-5075

\section{Refêrencia eletrónica}

Elsa Peralta e Joana Gonçalo Oliveira, « Pós-memória como herança: fotografia e testemunho do "retorno" de África », Configurações [Online], 17 | 2016, posto online no dia 30 junho 2016, consultado o 19 abril 2019. URL : http://journals.openedition.org/configuracoes/3290; DOI : 10.4000/ configuracoes.3290 
Peralta, Elsa; Oliveira, Joana Gonçalo - Pós memória como herança:

fotografia e testemunho do "retorno" de África. Configurações, vol. 17, 2016, pp. 181-197

\title{
Pós-memória como herança: fotografia e testemunho do "retorno" de África
}

\author{
ELSA PERALTA* \\ CEC, Universidade de Lisboa \\ JOANA GONÇALO OLIVEIRA** \\ Universidade de Lisboa
}

\section{Resumo}

Este artigo busca um entendimento possível para qualificar e testemunhar as implicações do "retorno" dos nacionais ao território português, após o processo de descolonização dos territórios africanos, que estiveram sob a administração portuguesa. Seguindo a história, e a memória, e suas heranças, caminhamos em direção a este evento que convencionamos chamar um dos pontos negros da história, refletindo o valor ético e analítico do conceito de rememoração e de arquivo, no decurso de uma exposição que pretendeu ver outros caminhos possíveis.

Palavras- chave: memória, testemunho, arquivo, descolonização portuguesa, retornar.

\begin{abstract}
Postmemory as an inheritance: photo and testimony of the "return" of Africa

This article offers a possible understanding of the "return" of Portuguese-controlled territory to African nations in order to qualify and bear witness to the implications of Portuguese decolonization. In following the story, memory, and their inheritances, we walk toward this event, which we might conventionally describe as one of "the black spots of history-thus reflecting the ethical and analytical value of the concept of recollection and archive in the course of representing other possible paths.
\end{abstract}

Keywords: memory, testimony, archive, Portuguese decolonization, return.

\footnotetext{
* Investigadora FCT do Centro de Estudos Comparatistas da Universidade de Lisboa. Email: elsa. peralta@campus.ul.pt.

** Doutoranda de Antropologia no Instituto de Ciências Sociais da Universidade de Lisboa. Email: joana.facto@gmail.com.
} 


\section{Résumé}

La postmémoire comme héritage : photographie et témoignage du "retour" d'Afrique Cet article cherche un arrangement possible pour qualifier et témoigner des implications du « retour » des portugais sur leur territoire après le processus de décolonisation des territoires africains sous administration portugaise. Sur les traces de l'histoire, de la mémoire et de leurs héritages, nous marcherons en direction de cet événement conventionnellement désigné comme un des points noirs de l'histoire, tout en réfléchissant à la valeur éthique et analytique des concepts de remémoration et d'archive, au long d'une exposition qui a cherché à examiner d'autres chemins possibles.

Mots-clés : mémoire, témoignage, archive, décolonisation portugaise, rapatriés.

\section{0 "retorno": definindo os limites do acontecimento histórico}

O que foi o "retorno"? Enunciar esta questão é denunciar um desconforto. Um desconforto, antes de mais, analítico, evidenciando desde logo a suspeita subjacente a esta classificação nominal e normativa - daí colocarmos o nome retorno entre aspas. Tal desconforto verte-se então em reclamação de um estatuto conceptual/analítico: $\mathrm{O}$ que foi o "retorno" (enquanto acontecimento histórico)?; o que é o "retorno" (enquanto evento memorial)?

Enquanto acontecimento histórico, o "retorno" corresponde ao movimento migratório despoletado pela descolonização portuguesa dos territórios africanos sob sua administração. A mudança de regime em Portugal, com o 25 de Abril de 1974, põe fim à política colonialista e bélica do Estado Novo erigida em defesa da integridade territorial e política de Portugal Continental e Ultramarino, contra as aspirações independentistas dos movimentos de autodeterminação organizados nos territórios coloniais ${ }^{1}$. O derrube do Estado Novo e o fim das guerras de libertação travadas em Angola, na Guiné-Bissau e em Moçambique abrem assim o caminho para a independência dos territórios coloniais portugueses ${ }^{2}$.

1 Em 1961, um movimento anticolonial manifestou-se em Angola, marcando o início do que ficou designado por Guerra Colonial Portuguesa. Em Angola, os movimentos de libertação nacional haviam-se começado a estruturar a partir da década de 1950: o MPLA (Movimento Popular de Libertação de Angola, fundado em 1956), a UPA/FNLA (Frente Nacional de Libertação de Angola, cuja origem remonta à União das Populações do Norte de Angola de 1954) e a UNITA (União Nacional para a Independência Total de Angola, 1966). Em Moçambique, as operações de guerrilha começaram em 1964, comandadas pela FRELIMO (Frente de Libertação de Moçambique), movimento nacionalista criado em 1962. A guerra de independência na Guiné começou em 23 de janeiro de 1963, por iniciativa do PAIGV (Partido Africano para a Independência da Guiné e Cabo Verde ), partido fundado em 1956 por Amílcar Cabral.

2 Portugal alinha-se assim finalmente com a vaga internacional da descolonização iniciada com a independência da Índia face ao Império Britânico em 1947, vaga que ganhou força internacional com a chamada Declaração Anticolonialista da ONU - Resolução 1514 (XV) da Assembleia Geral de 14 de dezembro de 1960. 
As independências das colónias portuguesas em África ${ }^{3}$, iniciadas em 1973 com a declaração unilateral da República da Guiné-Bissau (reconhecida por Portugal em 10 de setembro de 1974), sucedem-se durante o ano de 1975. Em Moçambique, a independência é proclamada em 25 de junho de 1975, com a FRELIMO (Frente de Libertação de Moçambique) a tomar o comando do país, embora enfrentando doravante a resistência armada da RENAMO (Resistência Nacional Moçambicana). Cabo Verde torna-se independente em 5 de julho de 1975 e São Tomé e Príncipe em 12 de julho de 1975. Em Angola, a pulverização do poder no território torna a transferência de soberania mais difícil, embora a independência do novo país tivesse sido proclamada a 11 de novembro de 1975. O Acordo de Alvor, assinado entre o Governo Português e os três movimentos de libertação (FNLA, MPLA e UNITA) a 15 de janeiro de 1975, havia previsto que a independência de Angola no dia 11 de novembro fosse liderada pelas três forças políticas e com unidade entre as populações negras, brancas e mestiças. No entanto, os princípios do acordo acabaram por ser gorados e os três movimentos de libertação, apoiados nos seus alinhamentos internacionais, prosseguiram uma luta pelo poder (Henriksen, 1976).

Se no curso dos anos em que durou o conflito armado nas colónias portuguesas (1961-1974), as populações colonas - antigas ou recentes - pareciam não ponderar a possibilidade do regresso à metrópole, verificando-se aliás movimentos populacionais significativos entre a ex-metrópole e as colónias nesses anos (Castelo, 2007), no imediato posterior ao 25 de Abril de 1974 em Portugal, essa possibilidade começa a ponderar-se, ainda que tenuemente. Em 5 de outubro de 1964, o jornal Notícias de Lourenço Marques, fazia capa com um manifesto de certeza: “Estamos e ficaremos!”. Já em 27 de junho de 1975, o jornal luandense A Província de Angola perguntava em tom de perplexidade: “O que faz partir as gentes?” (Góis, 2016). O futuro das colónias não era então ainda claro $^{4}$, embora dois meses após a mudança de regime em Portugal, alguns tivessem já cautelosamente tomado a iniciativa da partida. A grande vaga migratória acontece, porém, apenas a partir de meados de 1975, quando as lutas pelo poder entre os diferentes movimentos armados em Angola criam uma situação de colapso da ordem pública e de violência arbitrária.

$3 \mathrm{Na}$ Índia, a resistência à dominação portuguesa toma expressão no contexto da independência indiana concedida pelos britânicos, em 1947. Tendo Portugal recusado aceder ao pedido de rescindir da sua posse, e com o apoio do Tribunal Internacional e da Assembleia das Nações Unidas, a União Indiana invade em 1961 os territórios de Goa, Damão e Diu, integrando o Estado Português da Índia no seu território. Timor Português, atual Timor-Leste, proclamou unilateralmente a sua independência em 1975, mas foi anexado no mesmo ano pela Indonésia, em 15 de julho de 1976. Quanto a Macau, adquire em 1976 o estatuto especial de "território chinês sob administração portuguesa”, tendo a sua soberania sido definitivamente transferida para a República Popular da China no dia 20 de dezembro de 1999.

4 Nesse contexto ensaia-se ainda um leque de hipóteses políticas para o futuro das colónias, situado entre o "federalismo" e a "independência" (Góis, 2016). 
Como resultado da descolonização, estima-se que entre 500000 e 800000 colonos portugueses tenham abandonado a sua residência em África (Kalter, $2016)^{5}$. Através de uma ponte aérea que envolveu o exército e a aviação civil portugueses, com o apoio da aviação americana, russa, britânica, belga e alemã, 260000 indivíduos foram evacuados de Angola, entre meados de julho e novembro de 1975. Durante o pico da ponte aérea, uma média de 7000 pessoas chegaram ao aeroporto de Lisboa todos os dias (Kalter, 2016). De Moçambique, as vagas mais intensas aconteceram primeiro no final do verão de 1974, a partir do Acordo de Lusaca e dos acontecimentos de 7 de setembro, e depois já em 1976, quando a convivência entre os colonos brancos que decidiram permanecer no território e o novo regime estabelecido se deteriora. Na sua maior parte, estas populações optam por Portugal como terra de "retorno", fazendo uso de laços familiares ainda não quebrados para prover ao acolhimento na antiga metrópole. Chegam destituídas, com a roupa que trazem no corpo, deixando para trás todos os seus bens materiais, já que podiam apenas trazer consigo uma muito pequena quantidade das suas economias. Mas outras possibilidades se delinearam, sobretudo a África do Sul e outros países africanos governados por minorias brancas como a então Rodésia e a Namíbia, sob protetorado sul-africano, e também o Brasil, onde então governava uma ditadura militar, o que podia agradar a uma população pouco dada a arroubos revolucionários e também onde estava estabelecida uma diáspora portuguesa com ligações familiares a populações coloniais, sobretudo as oriundas de Angola. Estes nunca seriam contabilizados nas estatísticas do "retorno", fazendo impossível estimar o volume da massa humana envolvida no fenómeno. No seu seio desenharam-se quadros de vidas díspares, atravessados por diferentes casualidades históricas, oportunidades económicas, e idiossincrasias pessoais.

Esta é, com efeito, uma população heterogénea. De diferentes classes, fenótipos, géneros e idades, com ligações mais fortes ou mais ténues à realidade portuguesa e com diferentes graus de participação no sistema colonial. Alguns pertenciam a uma vaga de colonização antiga, chegados a África no quadro dos projetos de colonização oficial de Angola de finais do século XIX. Outros formavam um contingente populacional muito mais numeroso envolvido nas migrações do pós-guerra (Castelo, 2007). Mas oficialmente, bem como coloquialmente, todos foram nomeados nessa categoria única e abrangente de "retornado". A categoria surge pela atuação do Estado português na resposta ao movimento migratório massivo das colónias. Dessa atuação resulta a criação do Instituto de Apoio ao Retorno de Nacionais (IARN) ${ }^{6}$, em 1975, assim

5 A estatística do retorno é vaga e imprecisa. Segundo a estatística estimada por Rui Pena Pires (Pires, 1984), foram cerca de 500000 os indivíduos que chegaram à antiga metrópole entre 1974 e 1975 .

6 O IARN foi criado em 1975 pelo Decreto-Lei n. ${ }^{\circ}$ 169/75 de 31 de março em virtude do Grupo de Apoio aos Desalojados do Ultramar (GADU) criado em junho de 1974 ter deixado de conseguir 
consagrando, primeiro normativamente, e depois, no senso comum, o nome "retorno", bem como o adjetivo que lhe deriva, "retornado". Se retorno, entendido à letra, é o ato ou efeito de voltar ao ponto de onde se partiu e retornado é aquele que retornou, muitas das pessoas incluídas nessa categoria rejeitam a classificação. Um terço deles já havia nascido nas ex-colónias, não se percecionando como "retornados", preferindo autodefinir-se como "refugiado" ou "desalojado".

A classificação importa, contudo, menos pela sua exatidão formal e mais pelo seu alcance ideológico. Nomear estas pessoas enquanto "retornados" - e não como refugiados das guerras civis entre os movimentos de libertação - é evitar concebê-las como vítimas de um processo desastroso (assim o entendem) conduzido pelas forças revolucionárias que então lideravam os destinos do país. É também classificá-las na sua condição transitiva - de colono - beneficiária da doutrina do salazarismo e do sistema colonial, assim retirando-a do quadro mais vasto do colapso do domínio colonial europeu em África eclodido desde os anos 1950 (Kalter, 2016).

A historiografia do "retorno" está ainda largamente por fazer. Com exceção do trabalho de Rui Pena Pires, de 1984, no qual se traça uma sociografia dos "retornados" ", é francamente parca a produção académica sobre este tema. A História de Portugal, dirigida por José Mattoso (1993-1995), não dedica mais que dez páginas ao tema nos oito volumes que compõem a coleção ${ }^{8}$ e a História da Expansão Portuguesa, dirigida por Francisco Bethencourt e Kirti Chaudhuri (1999), embora dedique um capítulo ao tema, não vai mais além do que recuperar o estudo anteriormente referido de Rui Pena Pires, com um contributo deste no volume 5 da coleção9 . Para além de assinaláveis exceções, estranhamente as mais consistentes oriundas da academia estrangeira ${ }^{10}$, são quase nenhuns os estudos sistemáticos que aprofundem as muitas dimensões que compõem a complexidade do fenómeno. As grandes generalizações da estatística sociométrica ou da cronologia histórica, embora necessárias, não permitem contudo identificar o sujeito da história para além do positivismo dos factos, pelo que estes mesmos factos assim são situados fora da sua longa duração e da esfera da vida. São, portanto, factos sem arquivo que, assim, se vertem facilmente em interpretações de senso-comum, como aquela segundo a qual a população "retornada" terá tido uma integração notável na sociedade

responder às necessidades reais, tal o fluxo de retornados que chegavam das ex-colónias. O IARN foi extinto, em 1981, pelo Decreto-Lei n..$^{\circ}$ 97/81, de 2 de maio. A história do IARN e da sua atuação durante esses anos está ainda largamente por fazer.

7 Assente na caracterização da população retornada e estabelecida em Portugal após as descolonizações, com base nas variáveis origem e distribuição regional, estrutura por idade e sexo, qualificações escolares e estruturas socioprofissionais.

8 Ferreira (1993: 7-285).

9 Pires (1999: 182-196 e 212-213).

10 De assinalar em particular o trabalho de Lubkemann (2002 e 2005). 
portuguesa, sem que se conheçam os modos, as contradições, as negociações e as complexidades dessa integração.

Sabe-se, portanto, muito pouco acerca desse acontecimento histórico que ficou nomeado como "retorno", desde a decisão da vinda ou a fuga para Portugal até à dita integração na sociedade portuguesa. Sabe-se ainda menos sobre a forma como hoje, em Portugal, as pessoas e as instituições recordam o "retorno" e os "retornados".

\section{0 "retorno" enquanto evento memorial}

Regressamos então aqui à segunda das questões que enunciamos no início desta secção: o que é o "retorno" enquanto evento memorial?

Se nos dispusermos ao exercício, necessariamente imperfeito, de definição do conceito de memória, podemos considerar que a memória se refere "aos atos de recordação que ao mesmo tempo são atos de fala" (Albert Rosa et al., 2000:45). Quer isto dizer que a memória, longe de poder ser remetida para uma faculdade mental humana, deve antes ser entendida processualmente, ou seja, enquanto processo de enunciação de atos de recordação, assim articulados - em fala - para se tornarem memória. Estes atos de recordação, sujeitos a negociações e submetidos a esquecimentos, têm inevitavelmente uma existência social, pois são culturalmente articulados na e para a transmissão. Assim sendo, na medida em que se articula em fala, a memória constitui passados comuns, de acordo com referentes de imaginação coletiva, que são naturalmente cambiantes no tempo (Peralta, 2007).

Assim entendida a memória, podemos então dizer que, até há muito pouco tempo, o "retorno" foi um não-evento na memória coletiva nacional portuguesa. A par com as guerras coloniais em África, o "retorno" faz parte do conjunto dos legados negros do colonialismo português, com consequências para as populações colonizadas, mas também para as populações da metrópole colonizadora, quer seja para aqueles que se viram obrigados a lutar numa guerra mortífera, ou para as populações integradas no sistema colonial e que se viram subitamente destituídas. Considerando que o império foi e continua a ser o principal tropo de articulação da narrativa identitária portuguesa (Peralta, 2013), e tendo em conta que no seio dessa narrativa está fortemente enraizada a ideia da bondade inata do projeto imperial português, estas consequências desestabilizam profundamente a estrutura da imaginação mnemónica nacional.

No conturbado período pós-revolução, marcado pelo processo que ficou conhecido como $\mathrm{PREC}^{11}$, ora por razões de má consciência relativamente ao

11 PREC ou Processo Revolucionário em Curso corresponde a um período de atividades revolucionárias, decorrido entre o 25 de Abril de 1974 e a aprovação da Constituição Portuguesa, em Abril de 1976, com o seu auge no período crítico do Verão Quente de 1975, que culmina com o Golpe Militar de 25 de Novembro. 
processo de descolonização, ora devido às tensões manifestas no seio da sociedade civil e das forças armadas sobre a questão colonial, a guerra e o êxodo africano são "não-inscritos” (Gil, 2005) no espaço público - memorial e imagético - nacional. Dizemos que são não-inscritos assinalando, precisamente, essa não inscrição como ato, de omissão ou de esquecimento, sobre os acontecimentos que marcaram o fim do domínio colonial português. Trata-se assim, de acontecimentos que não aconteceram, desaparecendo, segundo José Gil, pelo "buraco negro que suga o espaço público"12. Não é, portanto, de estranhar que Eduardo Lourenço, escrevendo em 1977-78, note com perplexidade o facto de a "amputação" da "componente imperial da nossa imagem" não ter provocado conturbações maiores (Lourenço, 1978: 43). Na verdade, a partir das evidências que nos dá o tempo entretanto transcorrido, podemos dizer que não houve conturbações maiores porque tal amputação, embora tenha acontecido do ponto de vista político e normativo, não aconteceu enquanto imagem. Dos discursos políticos, às agendas das instituições culturais até às banais aceções do senso-comum, Portugal continua a imaginar-se enquanto império, imaginação essa na qual a guerra e o "retorno" continuam sem lugar de inscrição.

Até cerca dos anos 2000, essa não inscrição revelou-se pelo quase completo silêncio em relação a esses pontos negros que marcaram o fim do império português. Com exceção das leituras encriptadas de António Lobo Antunes ${ }^{13}$, da performance comemoracionista do Monumento aos Combatentes do Ultramar $^{14}$ (Peralta, 2014) e da institucionalização em Portugal, em 1996, da nosologia psiquiátrica da "Desordem de Stress Pós-Traumático" (Quintais, 2000), foram poucos os atos que, até então, implicassem o reconhecimento de um campo de experiência, também memorial, associado às consequências trágicas do fim do império português. No entanto, abria-se lentamente o caminho para o reconhecimento de um campo memorial associado ao colonial, primeiramente a partir do seu lado obscuro, traumático, onde a fala se começa a ensaiar a partir dos muitos ensombramentos que a guerra deixou nos corpos e nos pesadelos daqueles que a viveram. Os Estudos do Holocausto ${ }^{15}$, germinais para a consagração académica da teoria do trauma, fazem ressoar um pouco por toda a parte, no mundo académico e fora dele, o reconhecimento da figura histórica da vítima, cuja experiência, emocional e subjetiva, ganha no espaço público um campo de narração. O mercado editorial começa paulatinamente a inundar-se de memórias de ex-combatentes que querem livrar-se do peso do silêncio e reclamar o reconhecimento da verdade da sua experiência no seio da grande narrativa nacional ${ }^{16}$.

12 In http://www.revistatropico.com.br/tropico/html/textos/2845,1.shl, consultado 4 de abril de 2016. 13 Em particular em Memória de Elefante e Os Cus de Judas, de 1979, Conhecimento do Inferno, de 1980, e Fado Alexandrino, de 1983.

14 Inaugurado em 15 de janeiro de 1994, junto ao Forte do Bom Sucesso, em Belém

15 Ver Hayes \& Roth 2013.

16 São muitos os exemplos que não cabe aqui enunciar por não ser este o âmbito deste artigo. 
Contudo, o verdadeiro desvendamento acontece mais tarde, com o aparecimento de documentários, filmes, trabalhos de investigação e produção artística sobre a guerra, com destaque para o documentário Guiné-Bissau: As duas faces da guerra (2009), co-realizado por Diana Andringa e Flora Gomes e para a série documental A Guerra (2012) de Joaquim Furtado, que permitem inscrever amplamente o tema da guerra na historiografia e no senso-comum sobre o colonialismo português ${ }^{17}$. Só então é que o "retorno" ganha a possibilidade de um espaço de inscrição na memória nacional. Até esse momento, e salvo algumas exceções quase invisíveis, tinha permanecido largamente ausente. Esse espaço de inscrição é conquistado, primeiramente, ao terreno da nostalgia pós-colonial, pela mão daqueles que, geralmente através de autobiografias ficcionadas ou romances testemunhais, memorializam o passado colonial como um "sonho dourado" que, súbita e inexplicavelmente, chegou ao fim. No relato desse sonho interrompido, a vida boa que "lá se levava", é lembrada com doçura, como quem lembra uma infância feliz e inconsciente. Como conta Júlio Magalhães no seu Os Retornados: Um Amor Nunca se Esquece, "Jogar à bola, grandes farras em garagens, a praia, a mini-Honda" e a "vida corria quase de forma perfeita...".18

Seria preciso pouco tempo até que a nostalgia perdesse a doçura e desse lugar ao repúdio e à manifestação do ressentimento. Uma repulsa que se derrama em urgência pela escrita de Isabela Figueiredo que, no seu Caderno de Memórias Coloniais, brade por entre golpes e revelações contra o colonialismo português: "Aquele homem branco não é o meu pai” ${ }^{19}$. Tal como uma menina que se faz grande e subitamente vê lampejos, ainda informes, de uma verdade que se revela sob um manto de mentiras e ilusões, Isabela acrescenta ao terreno fértil da nostalgia pós-colonial a condição estéril de desterrado:

Os desterrados, como eu, são pessoas que não puderam regressar ao local onde nasceram, que com ele cortaram os vínculos legais, não os afectivos. São indesejados nas terras onde nasceram, porque a sua presença traz más recordações. Na terra onde nasci seria sempre a filha do colono. Haveria sobre mim essa mácula. A mais que provável retaliação. Mas a terra onde nasci existe em mim como uma mácula impossível de apagar. Persigo oficiais marinheiros que trazem escrita, na manga do casaco, a palavra Moçambique. ${ }^{20}$

Dessa condição resulta a suspensão da perda; uma perda que nunca verdadeiramente se aceita, nem completamente se sacia. Se a quisermos colocar no

17 Não é o objetivo deste artigo fazer uma revisão da produção cultural, artística e literária, institucional e não institucional, sobre os temas da guerra e do retorno, pelo que nos resumimos a referências que consideramos paradigmáticas na análise que perseguimos.

18 Magalhães (2008: 18 e 19).

19 Figueiredo (2009: 53).

20 Idem, 133. 
campo da comparação pós-colonial e entendê-la, tal como Paul Gilroy (2005) o fez para o caso Britânico, no seu alcance psicanalítico, é uma perda que não foi lamentada, i.e., não foi inscrita no discurso enquanto fim. Isto dará lugar, ora à melancolia pós-colonial, com os seus engendramentos de cosmopolitismo civilizacional (se seguirmos a proposta de Gilroy), ora ao sintoma e à somatização (se seguirmos a teoria do trauma). Ambos, a melancolia e o sintoma, haveriam ainda de ser topos centrais na narração do "drama" dos "retornados" em atos memoriais tais como o romance O Retorno, de Dulce Maria Cardoso ${ }^{21}$, de 2011, a série televisiva E depois do Adeus, de $2012^{22}$, e ainda o filme Tabu, de Miguel Gomes ${ }^{23}$, todos num momento ou noutro, fazendo brotar de um corpo de desejo e de repressão, a melancolia da perda pós-colonial.

\section{Retornar - Traços de Memória: imaginação e testemunho}

A circunscrição que tem vindo a ser discutida, em torno do desconforto analítico que o "retorno" traz, lançou as bases para a criação da exposição Retornar - Traços de Memória, curada por Elsa Peralta e com cocuradoria de Joana Oliveira. Enfatizando as questões de fundo memorial, assinalou-se os 40 anos do momento do "retorno" de nacionais, o qual conheceu o seu auge com a ponte aérea de 1975 . Realizada no âmbito do programa cultural da Câmara Municipal de Lisboa, a exposição propôs-se discutir as condições e as implicações que este evento situa na sociedade portuguesa, inscrevendo-a no espaço público político, como um ato de fala sequencial aos atos enumerados acima. Retornar é, nesta senda, uma exposição sobre a memória do "retorno" e, por relação, sobre a memória do império - e da potência do seu fim - na sociedade portuguesa contemporânea. Uma memória feita de fontes históricas, testemunhos pessoais, fotografias e conceitos artísticos. No sentido de dar corpo à complexidade que se joga entre as diferentes matérias a serem exibidas, pretendeu-se jogar olhares cruzados, originários de diferentes campos da arte, da literatura, da antropologia, da história, da política, para pensar e refletir sobre esta memória a partir do seu lastro no tempo presente.

Em jeito de apresentação sumária das diferentes seções que compuseram a exposição, a qual pretendeu arquivar toda a memória que se fez fértil no curso de uma investigação sobre o tema ${ }^{24}$, foram criados quatro arquivos: "Arquivo"; "Atlas"; “Alheava_Para Depósito"; e “Testemunho". “Arquivo”, composto por três núcleos temáticos, apresentou uma contextualização do evento do

21 Cardoso (2011).

22 Série televisiva produzida pela RTP que retrata Portugal no rescaldo do 25 de Abril a partir da saga da família Mendonça, uma família de "retornados" de Angola. Ver mais em http://www.rtp.pt/ programa/tv/p28774\#sthash.1WjX1vP1.dpuf.

23 Ver em http://www.osomeafuria.com/films/3/35/

24 Sobre a investigação em curso que esteve na base da exposição Retornar - Traços de Memória ver http://www.retornar-tracosdememoria.pt/projecto/ 
“retorno", desde as migrações coloniais, à descolonização e aos deslocamentos populacionais que os acompanharam. Através de fragmentos documentais justapostos, alternando documentos biográficos com documentos informativos, pretendeu ser um projeto aberto e suscetível de múltiplas combinações. "Atlas", apercebendo-se da memória na sua apropriação do tempo passado, num possível regresso ao que foi vivido, deu a ver os gestos, os caminhos, os risos, as poses, as árvores do tempo que se constitui em memória nos álbuns de família dos portugueses que viveram nas ex-colónias africanas antes do "retorno". A série apresentada revela e reflete o sentido que os ecos do passado trazem à vida, num constante movimento temporal, sem sentido de continuidade. "Alheava_Para Depósito” foi criado pelo artista Manuel Santos Maia, ao longo do seu percurso enquanto autor. A partir da sua herança familiar e seu percurso biográfico, o artista presentificou os legados coloniais através de objetos como fotografias, filmes, álbuns familiares, selos, documentos ou livros escolares, para reclamar a necessidade de não esquecer. "Testemunho" apresentou sequencialmente excertos de entrevistas a pessoas cujas histórias estão relacionadas com o "retorno", incitando os participantes a compreender como a experiência histórica é vivida como experiência pessoal, emocional e sensorial. Com doze fotografias de rostos testemunhais da autoria de Bruno Simões Castanheira, as quais vivem acompanhadas pela audição da voz própria, “Testemunho" deu a ver um cenário para sustentar a presença do passado e reconhecer o valor da experiência humana da perda, do sofrimento e da redenção.

Inscrever no espaço público estas distintas formas testemunhais que os nomeados "retornados" trazem nas algibeiras da vida, gerou uma atenção perspicaz relativa à ideia de pensar o "retorno" a partir de "um ato de começar que se insere no movimento de continuar, abrindo uma distância" (Molder, 2011: 101). Abrir uma distância é para o caso, apreender os diferentes testemunhos, os diferentes modos de apresentar a informação, as fontes históricas, e os acontecimentos aí apercebidos, na conceção de $u m$ arquivo possível. Arrumando todos os fantasmas reconhecidos e os outros que aqui foram convidados a vir, propôs-se aceitar o paradoxo de um ato que simplifica ao mesmo tempo que amplia as diferentes formas testemunhais. Desdobrando os testemunhos no tempo, para o pensamento instalar em si o tempo, trazendo-o ao presente, limpando as poeiras e criando um destino para assentarem (Gil, 1984).

Como refere George Didi-Huberman, criar um arquivo é, no seu campo de ação, "criar a possibilidade do testemunho, face ao inevitável desaparecimento da testemunha e à consequente impossibilidade do testemunho". O testemunho/arquivo urge pela eminência do desaparecimento do testemunho (do facto, mesmo, da irrepetibilidade da experiência) e da "irrepresentabilidade garantida do testemunho" (Didi-Huberman, 2012: 19)." Um testemunho que é uma ausência, balbuciada em atropelo pela voz daqueles a quem se convoca a fala, como podemos ler neste seu excerto transcrito: 
Eu acho que foi um trauma, acho que foi um trauma muito grande e foi um trauma que não foi acompanhado se calhar como devia ter sido. $\mathrm{O}$ meu tio mais novo, o irmão mais novo do meu pai, adora viver em Portugal e já não tem saudosismo nenhum, de espécie nenhuma. Claro fala da infância e da adolescência, com saudade, mas isso falamos todos, não é? Mas, por exemplo, a minha mãe, carrega muito isso, sempre, e há pessoas a quem custa mais, há pessoas a quem custa menos, foi tudo muito de repente. Os amigos ficaram espalhados, uns no norte, outros no sul, outros no Brasil e portanto perdeu-se tudo, perdeu-se quadros de referência, locais e objetos. ${ }^{25}$

Ao expor a perplexidade do que aconteceu à vida no testemunho direto, correndo em frente para não viver "a eminência do desaparecimento do testemunho", o que podemos também ler neste excerto é a natureza da condição não generalizável com que devemos compreender a "massa" de portugueses que "retornaram". É um excerto audível dos muitos sobrepostos na sala do "Testemunho", justapondo a ele outros testemunhos, reclamando essa dimensão complexa que parece parca nos estudos realizados até agora. O "desejo insaciável de generalidade" que frequenta algumas investigações preocupadas em fornecer um quadro de interpretação geral sobre os temas a estudar, traz mormente equívocos referentes à natureza do estudo a realizar em ciências humanas, particularmente porque o que se encontra em questão é pensar a experiência humana acomodando a sua variação ou pluralidade manifesta (Needham, 1971).

Entrementes, de forma a encontrar o lugar no arquivo para a memória vinda das fontes históricas - a qual se fez galopante no processo da investigação -, decidimos explorar um exercício de concatenação e conjugação desses elementos por relação aos testemunhos orais, dirigindo-os para a novidade de uma outra série de caminhos a experimentar. "Abrindo uma distância" assinalou-se a impossibilidade de continuar a pensar o "retorno" na sua natureza normativa, como se tratasse de uma evidência linear da história, como se fosse expectável este desfecho. Na voz dos que o viveram, não se ouvem expectativas; apenas alívios e mágoas:

Mas fomos vencendo, são situações que conseguimos superar, hoje praticamente podemos dizer que estamos integrados na sociedade, dado ao nosso esforço, mas temos uma mágoa muito grande, guardamos uma mágoa muito grande para com os governantes, da altura, que procederam como procederam, entregaram-nos ao deus-dará, viemos porque enfim, muitos não vieram, não tiveram oportunidade de vir, foram mortos, foram perseguidos, mortos e essa mágoa perdura, perdura e vai acabar só após a nossa... quando fecharmos os olhos, porque nunca pensámos que nos tratassem como nos trataram. Abandonaram-nos completamente.

25 Todos os excertos de entrevista aqui citados foram realizados por Elsa Peralta no decorrer do projeto de investigação. 
Os testemunhos que dizem de si falam sobre diferentes sentenças perante o infortúnio de perder a terra onde se nasceu, ou se viveu. Por sua vez, evidenciam também o atropelo de ações e diligências tomadas para dar acompanhamento ao inesperado e ao súbito. Apesar de babélico na sua estrutura de ação, o Instituto de Apoio ao Retorno dos Nacionais foi prestando algum apoio aos milhares de portugueses que assentaram em solo português. A história de Portugal deste período é fértil em fraturas e a vida se fazia com poucas certezas um pouco por todo o lado.

Tu apanhavas dos dois lados, do que eu percebi e do que eu ouvia. Ou eras olhado por um lado mais conservador e xenófobo, como um português de segunda, fosses preto ou branco, e como primitivo, portanto como pouco dado a vida na metrópole porque muita gente veio para aqui para a cidade de Lisboa, ou então eras olhado por alguém mais de esquerda como o racista que aceitou viver naquelas condições durante aquele tempo todo como se todos os portugueses fossem fascistas por terem vivido numa ditadura durante tanto tempo. Tudo isso são simplificações da história que assustam e metem medo, a mim metem-me medo como é que se faz isso. Eu acho que não havia distância, tudo foi muito rápido, tudo foi muito precipitado, tudo era muito preto e branco, tudo era muito isso. Ainda é um bocadinho, há condescendência a ver as coisas, há vitimização, há violência a analisar os factos e acho que sim o retorno, mais do que uma condição de pessoas, acho que é quase que um exercício obrigatório de todos...

Focando assim a atenção aos vazios, aos silêncios, oferecidos por entremeio da fala de quem "retornou”, procura-se reconhecer e reclamar a ação transformadora do valor ético daquilo que não deve e não pode ser esquecido. Jeanne Marie Gagnebin, em seu livro Lembrar, Escrever, Esquecer, incita a pensar a força gestante do conceito de rememoração. Rememorar trata-se, em primeiro lugar, de fazer um exercício de desprendimento da tarefa do historiador - aquele que colige factos da história emprestando-lhes uma sequência linear. Em torno, exercitar a rememoração é explorar os recantos e "em vez de repetir aquilo de que se lembra, abre-se aos brancos, aos buracos, ao esquecido e ao recalcado, para dizer, com hesitações, solavancos, incompletude, aquilo que ainda não teve direito nem à Lembrança nem às palavras" (Gagnebin, 2006: 55). O convite é o de ver a potência do ato de lembrar, ou mais certeiro ainda, é apreender o ato de não esquecer. Para que este exercício se dê é requerido que a imaginação participe do ato de lembrar, tanto quanto do ato da fala, não sendo por isso requerida somente ao que ouve a testemunha. Cabe à imaginação compor em lembrança a experiência do que foi vivido, porque é a partir do seu poder de montagem que se consegue articular aquilo que até aí não tinha sido dito. Este exercício de montagem não está somente entregue à dimensão narrativa da vida; lança-se para outras paragens, outras matérias do mundo, neste caso, nas fotografias tiradas num tempo que não pode voltar 
atrás, até porque a fotografia regista precisamente isso, o tão glosado isto foi (Barthes, 2006). Foi essa outra intensidade, muda, que se pretendeu compor na série "Atlas" da exposição Retornar, assim convidando, não a um exercício de nostalgia, mas a olhar os gestos e as relações vividas que se encontram nas fotografias dos álbuns dos portugueses resgatadas a esse tempo.

Aperceber a vitalidade do trabalho da imaginação no fazer da própria memória, da lembrança é, também, olhar para a vitalidade das imagens e sua ação neste processo. Repetir, dessa feita, a vitalidade da imagem fotográfica enquanto fazedora dos atos memória, na composição de um ato de testemunho. Porque ler o mundo, e os acontecimentos que a história traz, sugerem-se demasiado complexos e fundamentais para estarem presos só à narração linguística. De forma que a narrativa se constitua é necessário que venha acompanhada, porque vem sempre, pela matéria do mundo, ligando assim, as "coisas do mundo segundo as suas "relações íntimas e secretas", as suas "correspondências” e as suas “analogias” (Didi-Huberman, 2013: 15). Tal como as fotografias do "Atlas", também o testemunho constitui-se em imaginação e
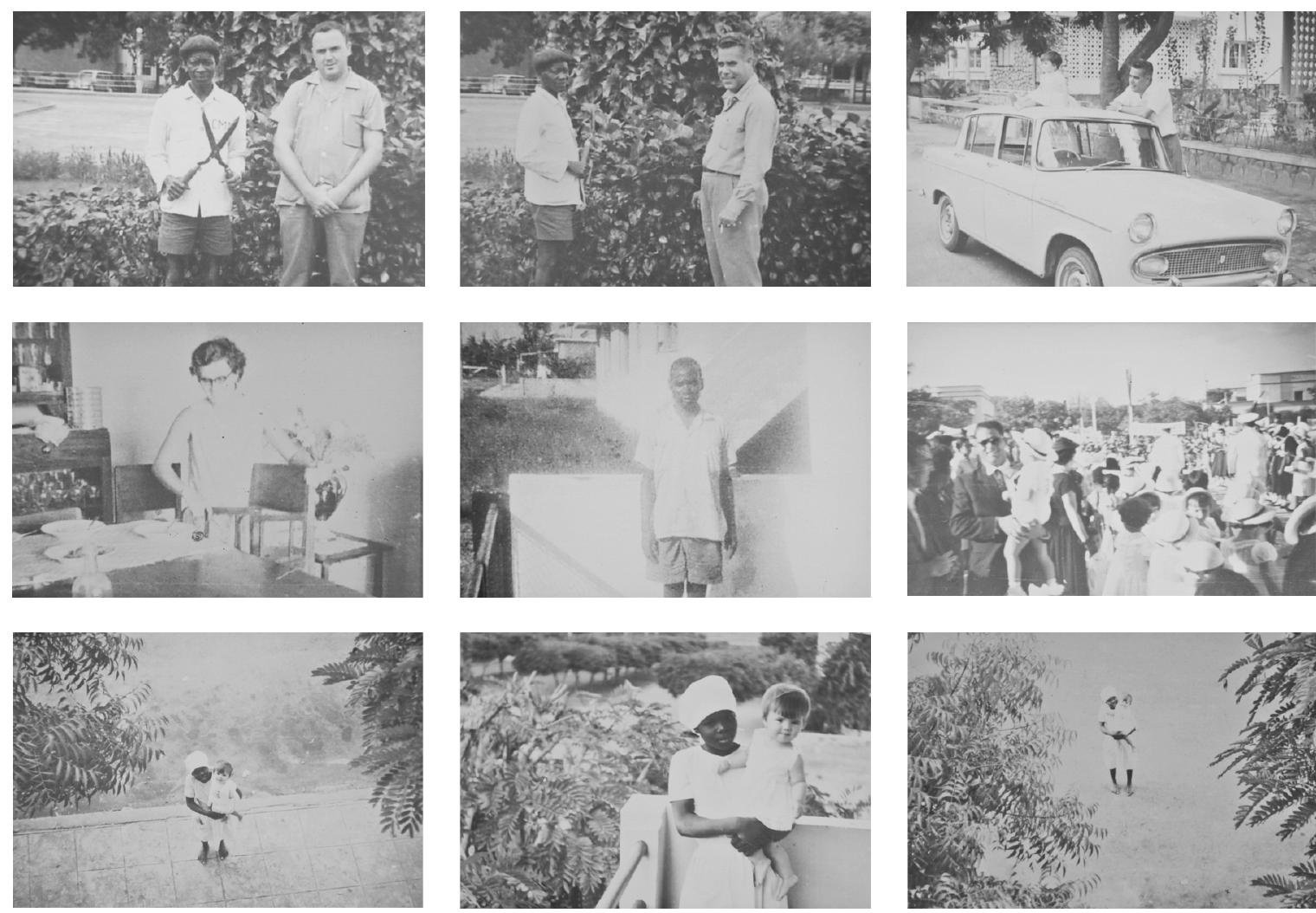
apresentação, liberto do ato de representação. Assim liberto, o testemunho traz em si o passado com o tempo que passou (Didi-Huberman, 2012), que desta feita se forma como um passado não literal e não linear; um passado, ademais, que reconhece a diferença entre o vivido e o lembrado:

... veio um avião da Rússia. Começaram a dizer que ele trazia o pessoal e em vez de vir para Portugal, não vinha para Portugal, ia para a Rússia. Isso é que era bom! Então estou a fugir de um sítio para vir meter-me noutro? Nem pensar nisso! [risos] ... Os únicos que vieram nesses aviões foram os oficiais. Nós? De cor ainda por cima? Enfiar ali dentro? Nem pensar nisso!

\section{Retornar como herança: uma crítica à pós-memória}

$\mathrm{Na}$ relação com o trabalho da imaginação, da sua competência em remontar o mundo, percebe-se então que tanto quem viveu a situação, quem viveu a vida lembrada, como quem é seu ouvinte, acede a toda a memória após a sua montagem. Neste sentido, a utilização das propostas que visam pensar a pós-memória na sua dimensão de uma pós vivência da situação, porque não a viveu diretamente, reclamando o trabalho da imaginação somente para quem ouve a lembrança, tal como notadamente o fez Marianne Hirsch (1997), parece reclamar um problema de grau em vez de natureza. Poderíamos esticar a corda e dizer que toda a memória é uma segunda memória, uma pós-memória, porque a verdade que se dá à lembrança instancia-se nas evidências imponderáveis, em vez de estar presa na positividade do acontecimento, da prova muda e certeira. Esta evidência imponderável está para lá da visão do raciocínio e da decisão; encontra-se do lado do sentimento e inclui subtilezas como um olhar, um gesto, um tom, uma imagem, cujas afinidades e diferenças dificilmente fazem sistema, isto é, entram na ordem do sentido explícito e das razões demonstradas (Csordas, 2004).

Chegados a uma terra que conheciam ou desconheciam consoante o tempo em que os seus antepassados tinham feito a viagem de ida, consoante o século, as fotografias que acompanharam os nacionais na sua viagem, as que conseguiram chegar, porque nem todos tiveram a possibilidade de trazer outros objetos - além da roupa que vinha a tapar o corpo -, convidam a registar uma sensação do tempo passado. A fotografia, na sua natureza muda, só consegue repetir "mecanicamente o que nunca mais poderá repetir-se existencialmente. Nela o acontecimento nunca se transforma noutra coisa: ela remete sempre o corpus de que necessito para o corpo que vejo: ela é o Particular Absoluto, a contingência soberana, impenetrável e quase animal, o Tal” (Barthes, 2006: 12). Quando sai da sua "contingência soberana" e é posta em ação, a fotografia muda cria um sentido, um sentido de passado no presente. Não obstante, "para os fantasmas desse mesmo passado isso não fará qualquer diferença. Eles permanecerão inalterados e intocados, como fantasmas ou fotografias que são, apesar de ainda 
assim poderem utilizar o poder para modificar o nosso presente e a nós mesmos" (Blaufuks, 2014: 93). Rememorar o valor ético da vida é presenciar esses fantasmas, chamando-os a nós sem medo da sua presença, da sua força, das suas heranças, e do seu toque transformador de passado no presente.
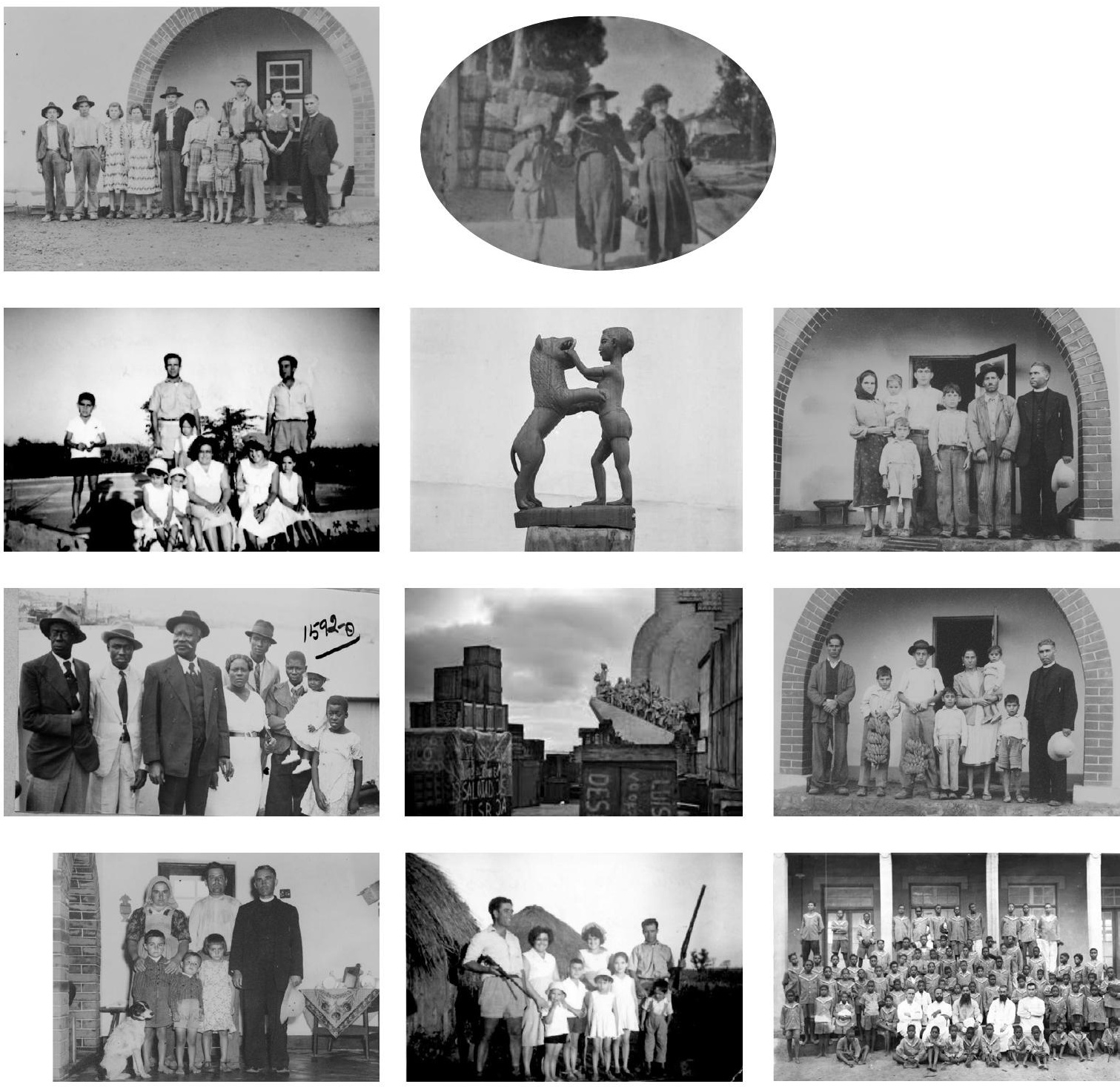


\section{Referências}

BARTHES, Roland (2006) (1980), A Câmara Clara. Lisboa: Edições 70.

BLAUFUKS, Daniel (2014), Toda a Memória do Mundo. Lisboa: Museu Nacional de Arte Contemporânea, Museu do Chiado Imprensa Nacional, Casa da Moeda.

CASTElo, Cláudia (2007), Passagens para África: o Povoamento de Angola e Moçambique com naturais da Metrópole (1920-1974). Porto: Edições Afrontamento.

CSORDAS, Thomas (2004), "Evidence of and for what?”. Anthropological Theory 4: 473-80.

DIDI-HUBERMAN, George (2012), Imagens apesar de Tudo. Lisboa: KKYM.

DIDI-HUBERMAN, George (2013), Atlas ou a Gaia Ciência Inquieta. Lisboa: KKYM.

FERREIRA, José Medeiros (1993), Portugal em Transe in História de Portugal, orientação de José Mattoso. Lisboa: Círculo de Leitores e Ed. Estampa, vol. VIII, 7-285.

GAGNEBIN, Jeanne (2006), Lembrar Escrever Esquecer. São Paulo: Editora 34.

GIL, Fernando (1984), Mimésis e Negação. Lisboa: Imprensa Nacional-Casa da Moeda, 15-34.

GIL, José (2005), Portugal Hoje - Medo de Existir. Lisboa: Relógio D’Água.

GILROY, Paul (2005), Postcolonial Melancholia. New York: Columbia University Press.

GÓIS, Bruno (2016), "Retornar à pergunta 'O que faz partir as gentes?”, in Elsa Peralta e Joana Oliveira (ed.). Retornar: Traços de Memória num Tempo Presente. Lisboa: Edições 70 (no prelo).

HAYES, Peter; ROTH, John K., (2013), The Oxford Handbook of Holocaust Studies. Oxford: Oxford University Press.

HENRIKSEN, Thomas H. (1976). "People's war in Angola, Mozambique, and Guinea-Bissau". The Journal of Modern African Studies, 14 (3): 377-399.

HIRSCH, Marianne (1997), Family Frames: photography, narrative and postmemory. Cambridge, Mass.: Harvard University Press.

KALTER, Christoph (2016), "Hotels for Refugees: Colonialism, Migration, and Tourism in Lisbon". Global Urban History, https:/globalurbanhistory.com/2016/03/02/hotels-for-refugees-colonialism-migration-and-tourism-in-lisbon/, consultado 2 de março de 2016.

LOURENÇO, Eduardo (1978), O Labirinto da Saudade: Psicanálise Mítica do Destino Português, Lisboa: Publicações Dom Quixote.

LUBKEMANN, Stephen C., (2002), “The moral economy of Portuguese postcolonial return”. Diaspora, 11 (2): 189-213.

LUBKEMANN, Stephen C. (2005), “The moral economy of non-return among socially-diverted migrants from Portugal and Mozambique", in L. Trager (ed.). Migration and Economy: Global and Local Dynamics. Society for Economic Anthropology Monographs. NY: Altamira Press.

MOLDER, Filomena (2011), "O que é uma inclinação natural?”, in Nuno Ventoinha (ed.), Linguagem e Valor: Entre o Tractatus e as Investigações. Lisboa: Instituto de Filosofia da Linguagem, 89-116.

NEEDHAM, Rodney (1971), Rethinking Kinship and Marriage. London: Tavistock.

PERALTA, Elsa (2007), “Abordagens Teóricas ao Estudo da Memória Social: Uma Resenha Crítica”. Arquivos da Memória: Antropologia, Escala e Memória, nova série, 2: 4-23.

PERALTA, Elsa (2013), “A composição de um complexo de memória imperial: O caso de Belém, Lisboa”, in Nuno Domingos e Elsa Peralta (ed.). Cidade e Império: Dinâmicas Coloniais e Reconfigurações Pós-coloniais. Lisboa: Edições 70, 361-407.

PERALTA, Elsa (2014), “O Monumento aos Combatentes do Ultramar: A Performance do Império no espaço sagrado da nação”, in Paula Godinho (ed.), Antropologia e Performance. Castro Verde: 100Luz, 213-236.

PIRES, Rui Pena (1984), Os Retornados: Um Estudo Sociográfico, Lisboa: Instituto de Estudos para o Desenvolvimento. 
PIRES, Rui Pena (1999), "O regresso das colónias”, in Francisco Bethencourt e Kirti Chaudhuri (org.), História da Expansão Portuguesa, Lisboa: Círculo de Leitores, volume 5, 182-196 e 212-213.

QUINTAIS, Luís (2000), As guerras coloniais portuguesas e a invenção da história: memória e trauma numa unidade psiquiátrica. Lisboa: Edições do Instituto de Ciências Sociais.

Submetido: 20-02-2016

Aceite: 24-06-2016 
